\title{
Development of In Vitro Drug-Induced Cardiotoxicity Assay by Using Three-Dimensional Cardiac Tissues Derived from Human Induced Pluripotent Stem Cells
}

\author{
Maki Takeda, PhD, Shigeru Miyagawa, MD, PhD, Satsuki Fukushima, MD, PhD, \\ Atsuhiro Saito, PhD, Emiko Ito, PhD, Akima Harada, MSc, Ryohei Matsuura, MD, Hiroko Iseoka, PhD, \\ Nagako Sougawa, PhD, Noriko Mochizuki-Oda, PhD, Michiya Matsusaki, PhD?, \\ Mitsuru Akashi, $\mathrm{PhD}^{3}$, and Yoshiki Sawa, MD, $\mathrm{PhD}^{1}$
}

An in vitro drug-induced cardiotoxicity assay is a critical step in drug discovery for clinical use. The use of human induced pluripotent stem cell-derived cardiomyocytes (hiPSC-CMs) is promising for this purpose. However, single hiPSC-CMs are limited in their ability to mimic native cardiac tissue structurally and functionally, and the generation of artificial cardiac tissue using hiPSC-CMs is an ongoing challenging. We therefore developed a new method of constructing three-dimensional (3D) artificial tissues in a short time by coating extracellular matrix (ECM) components on cell surfaces. We hypothesized that 3D cardiac tissues derived from hiPSC-CMs (3D-hiPSC-CT) could be used for an in vitro drug-induced cardiotoxicity assay. 3DhiPSC-CT were generated by fibronectin and gelatin nanofilm coated single hiPSC-CMs. Histologically, 3DhiPSC-CT exhibited a sarcomere structure in the myocytes and ECM proteins, such as fibronectin, collagen type I/III, and laminin. The administration of cytotoxic doxorubicin at $5.0 \mu \mathrm{M}$ induced the release of lactate dehydrogenase, while that at $2.0 \mu \mathrm{M}$ reduced the cell viability. E-4031, human ether-a-go-go related gene (hERG)type potassium channel blocker, and isoproterenol induced significant changes both in the Ca transient parameters and contractile parameters in a dose-dependent manner. The 3D-hiPSC-CT exhibited doxorubicin-sensitive cytotoxicity and hERG channel blocker/isoproterenol-sensitive electrical activity in vitro, indicating its usefulness for drug-induced cardiotoxicity assays or drug screening systems for drug discovery.

Keywords: 3D cardiac tissue, cardiotoxicity, drug screening

\section{Introduction}

$\mathbf{S}^{\mathrm{n}}$ NCE DRUGS ARE characterized by their safety and therapeutic efficacy, the discovery of new drugs requires a number of studies, including in vitro and in vivo animal/ clinical studies. ${ }^{1}$ The development of a large number of new drugs has been delayed or cancelled due to their unexpected side effects in the stage of clinical studies or even after marketing. ${ }^{2,3}$ Cardiovascular diseases are the main cause of death globally. ${ }^{4}$ In addition, cardiotoxicity is one of the leading causes of drug withdrawals. ${ }^{5}$ Typically, the cardiotoxicity of drugs is tested by an in vitro human ether-a-go-go related gene (hERG) assay, in vivo animal study, and then clinical studies. However, hERG assays and animal studies have been known to fail to appropriately detect the cardiotoxicity of drugs under conditions of actual patient use, partially because these screening studies are limited by the use of single non-myocyte cells in the hERG assay and by the intrinsically different functional and electrophysiological proprieties of animal models. ${ }^{6-16}$

The use of stem cell technology is a promising approach for drug discovery, since human induced pluripotent stem cells (hiPSCs) enable us to overcome those species differences. Furthermore, the pluripotency of stem cells may have

\footnotetext{
${ }^{1}$ Department of Cardiovascular Surgery, Osaka University Graduate School of Medicine, Suita, Osaka, Japan.

${ }_{3}^{2}$ Department of Applied Chemistry, Osaka University Graduate School of Engineering, Osaka, Japan.

${ }^{3}$ Building Block Science Joint Research Chair, Graduate School of Frontier Biosciences, Osaka University, Suita, Japan.
}

(C) Maki Takeda et al. 2018; Published by Mary Ann Liebert, Inc. This is an Open Access article distributed under the terms of the Creative Commons Attribution License, which permits unrestricted use, distribution, and reproduction in any medium, provided the original work is properly cited. 
the potential for high-throughput screening for both safety and therapeutic efficacy of drugs in vitro. ${ }^{17-19}$ Indeed, hiPSCs established from patients with specific genetic abnormalities, such as long QT syndrome ${ }^{20-22}$ or congenital chondropathy, ${ }^{23}$ were reported to be useful in screening candidate drugs to test their therapeutic efficacy.

Recently, a screening system for cardiotoxicity using cardiomyocytes derived from hiPSCs (hiPSC-CM) was explored. Although single-cell or monolayer cultures are widely used for such screening systems, some studies have suggested that cardiomyocytes cultured in a three-dimensional (3D) environment play a crucial role in pharmacologically induced responses. ${ }^{24-26}$ Various approaches to construct 3D artificial tissues have been examined to prove the safety of medications. Most of these studies have used specialized molds or scaffolds. ${ }^{26-29}$ Although specialized scaffolds make it possible to form 3D cardiac structures, those technologies are difficult to reproduce as a consequence of their complexity. The artificial scaffolds require consideration of the inhibition of cell-cell interaction or cell proliferation. Furthermore, in addition to the 3D structure, an extracellular matrix (ECM) is crucial to the function of the heart. ${ }^{30} \mathrm{We}$ therefore speculate that it may be necessary to develop appropriate cardiac tissues showing microstructures or pathophysiology similar to the native myocardium to evaluate cardiac toxicity accurately.

Our laboratory previously reported a new method of constructing 3D artificial tissues in a short time by coating ECM components onto cell surfaces. ${ }^{31}$ This method enabled the construction of 3D structures without the inhibition of cell-cell interactions and culture with ECM components. In this study, we hypothesized that an in vitro drug-induced cardiotoxicity assay using 3D cardiac tissues derived from hiPSCs (3D-hiPSC-CT) may be useful as a new standardized cardiotoxicity test. We examined the mechanical and electrophysiological responses of 3D-hiPSC-CT against known cardiotoxic drugs that had different effects on cardiomyocytes, including doxorubicin to evaluate cytotoxicity, E-4031, hERG-type potassium channel blocker to evaluate the arrhythmic effect causing QT prolongation or torsades de pointes, and isoproterenol, a nonselective betaadrenergic agonist to examine positive inotropy.

\section{Materials and Methods}

\section{Cardiac differentiation of hiPSCs}

hiPSCs (253G1; Riken, Ibaraki, Japan) were cultured and maintained in Primate ES Cell medium (ReproCELL, Kanagawa, Japan) with $4 \mathrm{ng} / \mathrm{mL}$ human basic fibroblast growth factor (bFGF; Wako, Osaka, Japan) on mouse embryonic fibroblast cells (ReproCELL). Cardiac differentiation was performed as follows: hiPSCs were dissociated using dissociation solution (ReproCELL) and transferred to an ultralow attachment culture dish (Corning, MA) in mTeSR1 (Stemcell Technologies, Canada) with Y-27632 (Wako). After the formation of embryoid bodies, the culture medium was exchanged for a differentiation medium that contained StemPro34 (ThermoFisher Scientific, MA), $2 \mathrm{mM}$ L-glutamine (ThermoFisher Scientific), $50 \mu \mathrm{g} / \mathrm{mL}$ ascorbic acid (Wako), and 1-thioglycerol (Sigma-Aldrich, St. Louis) and was supplemented with several human recombinant protein, including bone morphologic protein 4 , activin A, bFGF, and vascular endothelial growth factor (R\&D Systems, MN), and small molecules such as IWR-1 (Wako). hiPSC-CMs were maintained in DMEM (Nacalai Tesque, Kyoto, Japan) containing 10\% fetal bovine serum (FBS; Sigma-Aldrich).

\section{Construction of 3D-hiPSC-CT}

3D-hiPSC-CT were constructed as previously described. ${ }^{32}$ In brief, hiPSC-CMs were dissociated with $0.05 \%$ trypsinEDTA (ThermoFisher Scientific). The cells were suspended in $0.2 \mathrm{mg} / \mathrm{mL}$ fibronectin (Sigma-Aldrich) or gelatin (Wako) in phosphate-buffered saline (PBS; Nacalai Tesque) into a $24-\mathrm{mm}$ transwell with $3.0 \mu \mathrm{m}$ pore size (Corning) and incubated for $1 \mathrm{~min}$ at $500 \mathrm{rpm}$ using a shaking incubator (SI-300; AS ONE, Osaka, Japan). The cells in the insert were then centrifuged for $1 \mathrm{~min}$ at $1000 \mathrm{rpm}$. After each coating step, the cells were washed with PBS in the same way. These coating steps were repeated nine times (fibronectin: five times and gelatin: four times), and fibronectin and gelatin nanofilms (FG) were coated over a single-cell surface. To construct the multilayer tissue (3D-hiPSC-CT), FG-coated cells were seeded at $5 \times 10^{5}$ cells into a $6.5-\mathrm{mm}$ transwell with $0.4 \mu \mathrm{m}$ pore size (Corning), and the culture medium was added to a 6-well plate outside of inserts or FG-coated cells were seeded onto a 96-well plate. The 3DhiPSC-CT were incubated for 3-5 days, and the culture media were changed to DMEM containing 10\% FBS every other day.

\section{Quantitative real-time polymerase chain reaction}

Total RNA was isolated from hiPSCs and hiPSC-CMs using a PureLink RNA Mini Kit (ThermoFisher Scientific). Quantitative real-time polymerase chain reaction (qPCR) was performed using a SYBR Green and ViiA $7^{\mathrm{TM}}$ RealTime PCR System (ThermoFisher Scientific). All data were

Table 1. Sequences of the Primers and Probes for Quantitative Real-Time Polymerase Chain Reaction

\begin{tabular}{lll}
\hline Gene & \multicolumn{1}{c}{ Forward primer $\left(5^{\prime} \rightarrow 3^{\prime}\right)$} & \multicolumn{1}{c}{ Reverse primer $\left(5^{\prime} \rightarrow 3^{\prime}\right)$} \\
\hline OCT3/4 & GAAACCCACACTGCAGCAGA & TCGCTTGCCCTTCTGGCG \\
NANOG & CTCAGCTACAAACAGGTGAAGAC & TCCCTGGTGGTAGGAAGAGTAAA \\
LIN28 & CACGGTGCGGGCATCTG & CCTTCCATGTGCAGCTTACTC \\
$\alpha \mathrm{MHC}$ & GGGATAACCAGGGGAAGCACCAAGA & TGCCTCCCTCCCGGGACAAAAT \\
cTnT & AAAGCCCAGGTCGTTCATGCCC & CATTCCGGATGCGCTGCTGC \\
Nkx2.5 & ACCCTGAGTCCCCTGGATTT & TCACTCATTGCACGCTGCAT \\
GAPDH & GAAGGTGAAGGTCGGAGTC & GAAGATGGTGATGGGATTTC \\
\hline
\end{tabular}

$\alpha \mathrm{MHC}, \alpha$ myosin heavy chain; cTnT, cardiac troponin $\mathrm{T}$. 
normalized using glyceraldehyde-3-phosphate dehydrogenase (GAPDH) as control and evaluated using the deltadelta CT method. Primer sequences are listed in Table 1.

\section{Histology and immunohistolabeling}

hiPSC-CMs and 3D-hiPSC-CT were fixed with $4 \%$ paraformaldehyde. hiPSC-CMs and 3D-hiPSC-CT were labeled by primary antibodies such as anti-cardiac troponin $\mathrm{T}(\mathrm{cTnT}$, 1:200 dilution; Abcam, Cambridge, UK), anti-sarcomeric alpha actinin ( $\alpha$-actinin, 1:400; Sigma), anti-vimentin (1:100; Dako, Glostrup, Denmark), anti-connexin43 (1:100; Abcam), antiMLC2a (1:100; Synaptic Systems GmbH), anti-MLC2v (1:200; Proteintech, Rosemont) anti-fibronectin (1:200; Abcam), anti-laminin (1:30; Sigma), anti-collagen type I (1:100; Abcam), or anti-collagen type III (1:100; Abcam), followed by secondary antibodies such as AlexaFluor488 or AlexaFluor555 conjugated goat or donkey anti-mouse or anti-rabbit (ThermoFisher Scientific). Nuclei were counterstained with Hoechst33342 (Dojindo, Kumamoto, Japan) and assessed using confocal microscope (FLUOVIEW FV10i; Olympus, Tokyo, Japan).

\section{Field potential measurements}

The 3D-hiPSC-CT in the $6.5-\mathrm{mm}$ transwell was replaced on MED probe (MED-P545A; Alpha MED Scientific, Osaka, Japan) and incubated until cell attachment. Extracellular field potentials were recorded using a multielectrode array (MEA) system (MED64; Alpha MED Scientific) for $30 \mathrm{~min}$ at $37^{\circ} \mathrm{C}$.

\section{Lactate dehydrogenase release assay}

A lactate dehydrogenase (LDH) release assay was performed using an LDH Cytotoxicity Detection Kit (Takara Bio, Shiga, Japan). Doxorubicin (Wako) at $0.1,1,2,5$, or $10 \mu \mathrm{M}$ was added for $24 \mathrm{~h}$. After adding doxorubicin for $24 \mathrm{~h}$, the supernatants were then collected, and a mixture of diaphorase $/ \mathrm{NAD}^{+}$was added to each well. After incubation in the dark room for $30 \mathrm{~min}$ at room temperature, the absorbance was recorded on a microplate reader (DS Pharma Biomedical, Osaka, Japan) at a wavelength of $490 \mathrm{~nm}$ with a reference wavelength of $600 \mathrm{~nm}$. The experiments were performed in triplicate. The $\mathrm{LDH}$ release was determined as the percentage of LDH release compared with that of the vehicle control.

\section{Cell viability assay}

The cell viability was assessed using a Cell Counting Kit-8 (CCK8; Dojindo). Doxorubicin at $0.1,1,2,5$, or $10 \mu \mathrm{M}$ was added for $24 \mathrm{~h}$. After adding doxorubicin for $24 \mathrm{~h}$, the media were then changed to fresh media, and $10 \mu \mathrm{L} \mathrm{CCK} 8$ solution was added to each well for incubation for $2 \mathrm{~h}$ at $37^{\circ} \mathrm{C}$. Absorbance was recorded on a microplate reader at a wavelength of $450 \mathrm{~nm}$ with a reference wavelength of $630 \mathrm{~nm}$. The experiments were performed in triplicate. Cell viability was determined as the percentage of surviving cells compared with that of the vehicle control.

\section{Calcium transient measurement}

Calcium transient was assessed by FDSS/ $\mu$ CELL (Hamamatsu Photonics, Shizuoka, Japan). The 3D-hiPSC-CT were incubated in a loading buffer containing $5 \mu \mathrm{M} \mathrm{Cal}-$
$520^{\mathrm{TM}}$ AA (AAT Bioquest, CA) in PBS for $2 \mathrm{~h}$ at $37^{\circ} \mathrm{C}$. E4031 (Calbiochem Merck Millipore, Darmstadt, Germany) at 10,30 , or $100 \mathrm{nM}$ or isoproterenol (Calbiochem Merck Millipore) at 10,100 , or $1000 \mathrm{nM}$ was then added to the culture medium, and the fluorescence intensity of Cal-520 was monitored and recorded until $3 \mathrm{~h}$ after adding the drugs.

\section{Cell motion analyses}

Contractile property was assessed by a Cell Motion Imaging System (SI8000; SONY, Tokyo, Japan). Videos of the 3D-hiPSC-CT were recorded at a frame rate of $150 \mathrm{fps}$, a resolution of $1024 \times 1024$ pixels, and a depth of 8 bits. Subsequently, 10, 30, or $100 \mathrm{nM}$ of E-4031 or 10, 100, or $1000 \mathrm{nM}$ of isoproterenol was added to the culture medium, and the cell motion was monitored and recorded until $1 \mathrm{~h}$ after adding the drugs.

\section{Statistical analyses}

Data are expressed as the mean \pm standard deviation. Statistical significance was determined by Student's $t$-test (twotail) for comparisons between two groups. ${ }^{*} p<0.05$ was considered statistically significant and $* *$ indicates $p<0.01$.

\section{Results}

\section{Cardiomyogenic differentiation of hiPSCs}

hiPSCs were cardiomyogenically differentiated by the well-established culture protocol (Fig. 1A). After differentiation, hiPSC-CMs showed significantly lower expressions of undifferentiated markers, such as Oct3/4, Nanog, and Lin28, and significantly higher expressions of cardiac markers, such as $\alpha M H C, c T n T$, and $N k x 2.5$, than undifferentiated hiPSCs on qPCR (Fig. 1B). In addition, hiPSC-CMs expressed cardiacspecific structural proteins, such as cTnT, $\alpha$-actinin, MLC2a, and MLC2v, on immunohistolabeling (Fig. 1C). hiPSC-CM included cardiac troponin-positive cells $(57 \% \pm 4.0 \%)$ and vimentin-positive cells $(43 \% \pm 4.0 \%)$, which are markers of fibroblast and smooth muscle cells, respectively (Fig. 1D).

\section{Structural and electromechanical characters of 3D-hiPSC-CT}

The structure of 3D-hiPSC-CT was characterized by immunohistolabeling for structural proteins of the myocytes and ECM proteins.

As a result, 3D-hiPSC-CT displayed thick multilayers, with a maximum thickness of $50 \mu \mathrm{m}$. Cardiac-specific structural proteins, such as cTnT, $\alpha$-actinin, and connexin 43 , were clearly expressed, exhibiting a typical sarcomere structure and gap junctions in the majority of cardiac myocytes in the 3D-hiPSC-CT (Fig. 2A, B). In addition, the contractile protein isoform MLC2 $\mathrm{v}$ was predominantly expressed in cardiac myocytes (Fig. 2C). Furthermore, cardiac-specific matrix proteins, such as fibronectin, laminin, and collagen, were homogeneously expressed in the extracellular space of 3D-hiPSC-CT (Fig. 2D-G).

The electrical potential of the entire 3D-hiPSC-CT was assessed by the MEA system (Fig. 2H), showing spontaneous, synchronous, regular, and continuous beating of the tissue, indicating electrical linkage throughout the artificial tissue (Fig. 2I). 
A

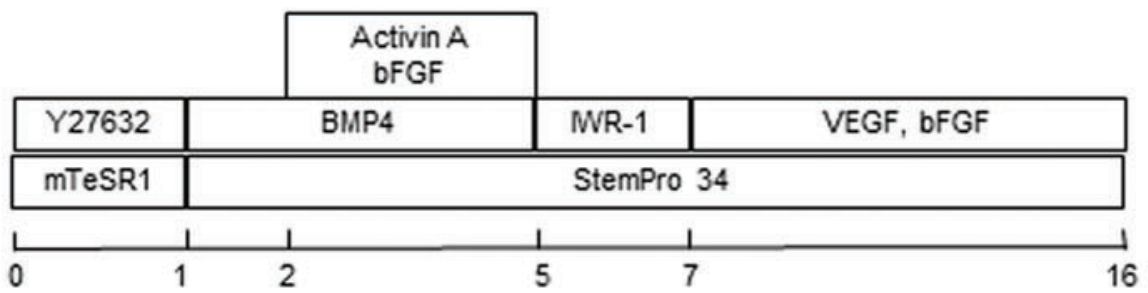

B
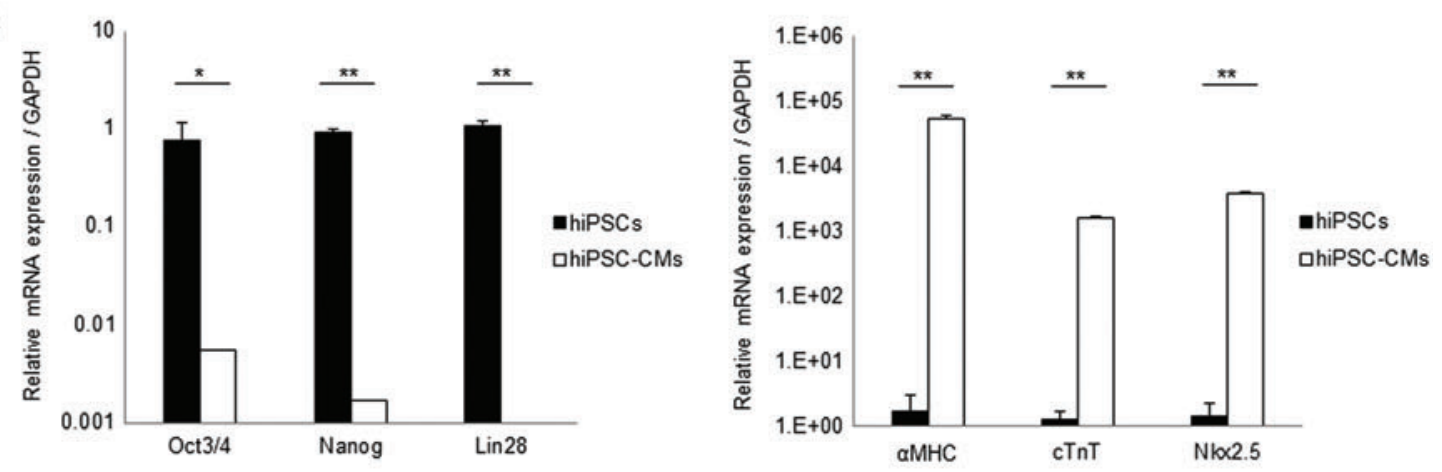

C
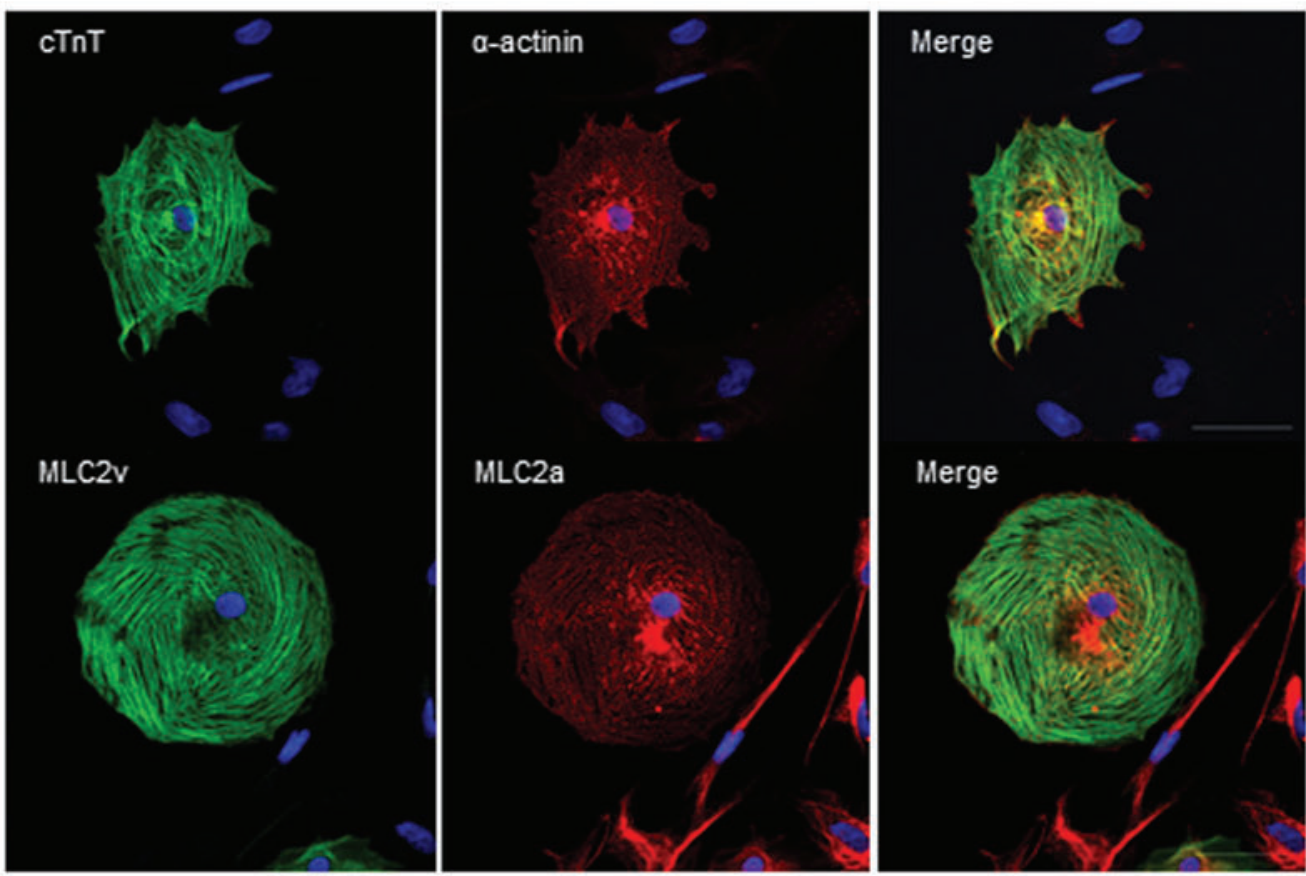

D
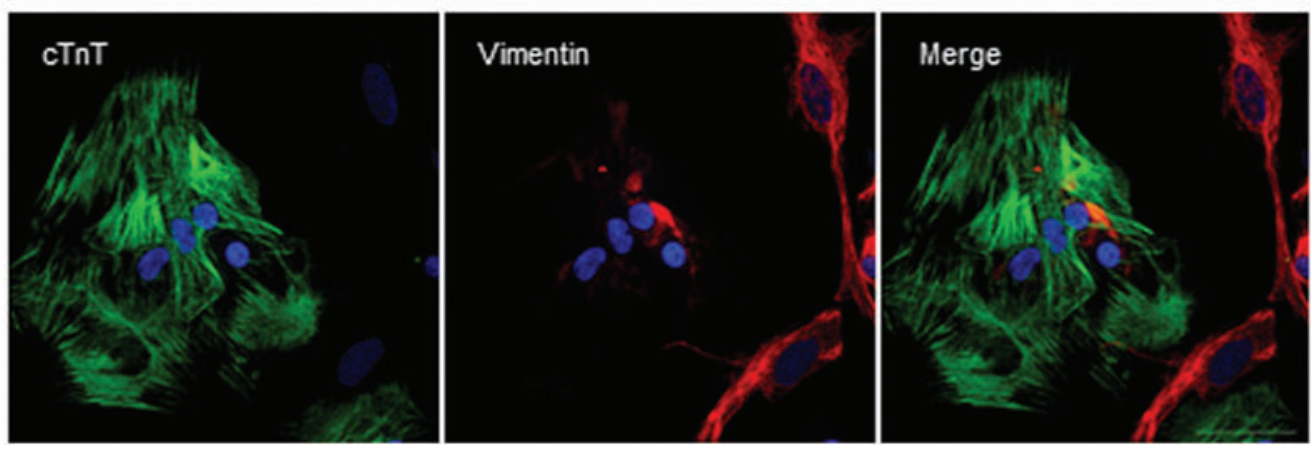

FIG. 1. Characterization of hiPSC-CMs. (A) Cardiac differentiation protocol, (B) mRNA expression of hiPSCs and hiPSC-CMs. $* p<0.05,{ }^{*} * p<0.01$. Immunostaining of hiPSC-CMs with $(\mathbf{C})$ anti-cardiac troponin $\mathrm{T}$ (green), anti-sarcomeric alpha actinin antibody (red) (top), anti-MLC2v (green), anti-MLC2a (red) (bottom), and Hoechst. (D) Immunostaining of hiPSC-CMs with anti-cardiac troponinT (green), anti-vimentin (red), and Hoechst. Scale bar: $50 \mu \mathrm{m}$. hiPSC-CMs, human induced pluripotent stem cell-derived cardiomyocytes. Color images available online at www.liebertpub.com/tec 

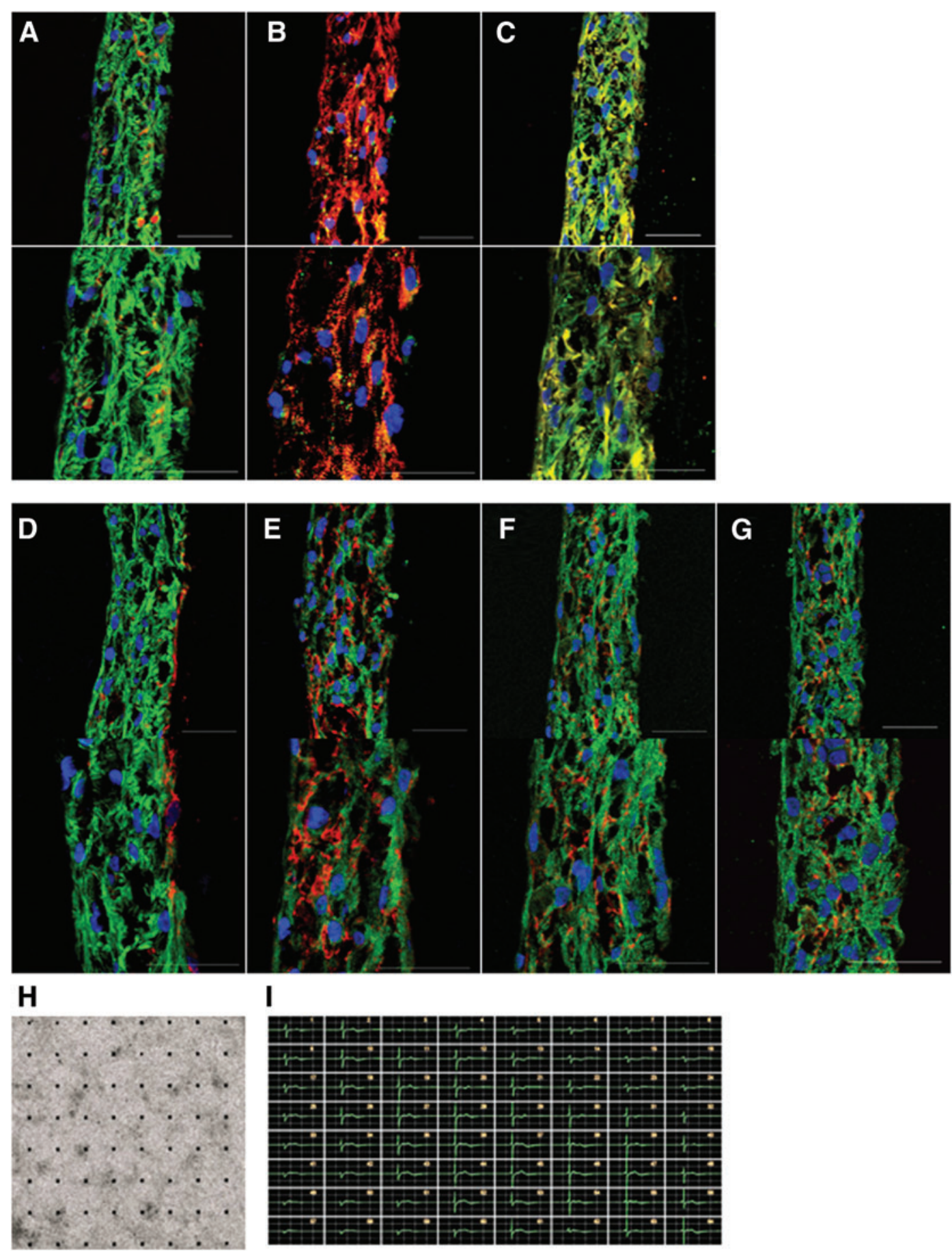

I

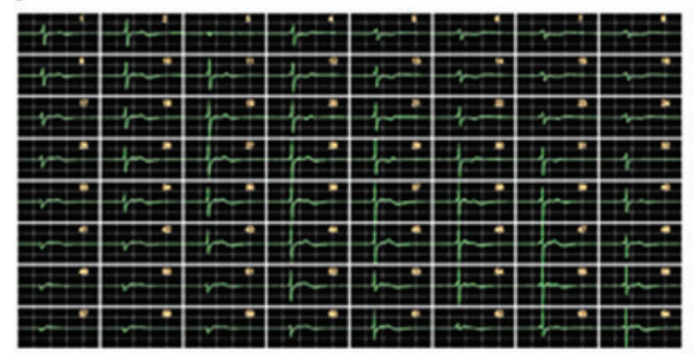

FIG. 2. Characterization of 3D-hiPSC-CT. Immunostaining of 3D-hiPSC-CT for (A) cardiac troponin T (green), vimentin (red), (B) connexin43 (green), sarcomeric alpha actinin (red), (C) MLC2v (green), MLC2a (red), and extracellular matrix proteins (D) cardiac troponin T (green), fibronectin (red), (E) cardiac troponin T ( green), laminin (red), (F) cardiac troponin T (green), collagen type I (red), (G) cardiac troponin T (green), collagen type III (red), and Hoechst. Scale bar: $50 \mu \mathrm{m}$. (H) Electrical and contractile properties of entire 3D-hiPSC-CT. 3D-hiPSC-CT plated on a microelectrode array probe. (I) Representative tracings of detected electrical potentials of 3D-hiPSC-CT. 3D-hiPSC-CT, three-dimensional cardiac tissues derived from hiPSC-CMs cardiac tissue. Color images available online at www.liebertpub.com/tec

\section{Drug-induced cytotoxicity of doxorubicin for 3D-hiPSC-CT}

Doxorubicin-induced cytotoxicity of 3D-hiPSC-CT was assessed by an LDH assay and CCK8 assay. As a result, doxorubicin induced release of LDH in 3D-hiPSC-CT in a dose-dependent manner. Doxorubicin at $5 \mu \mathrm{M}(145 \% \pm 48 \%$, $p<0.01$ vs. vehicle control) and $10 \mu \mathrm{M}(228 \% \pm 97 \%, p<0.01$ vs. vehicle control) induced a significant increase in LDH release (Fig. 3A). Doxorubicin also reduced the cell viability in 

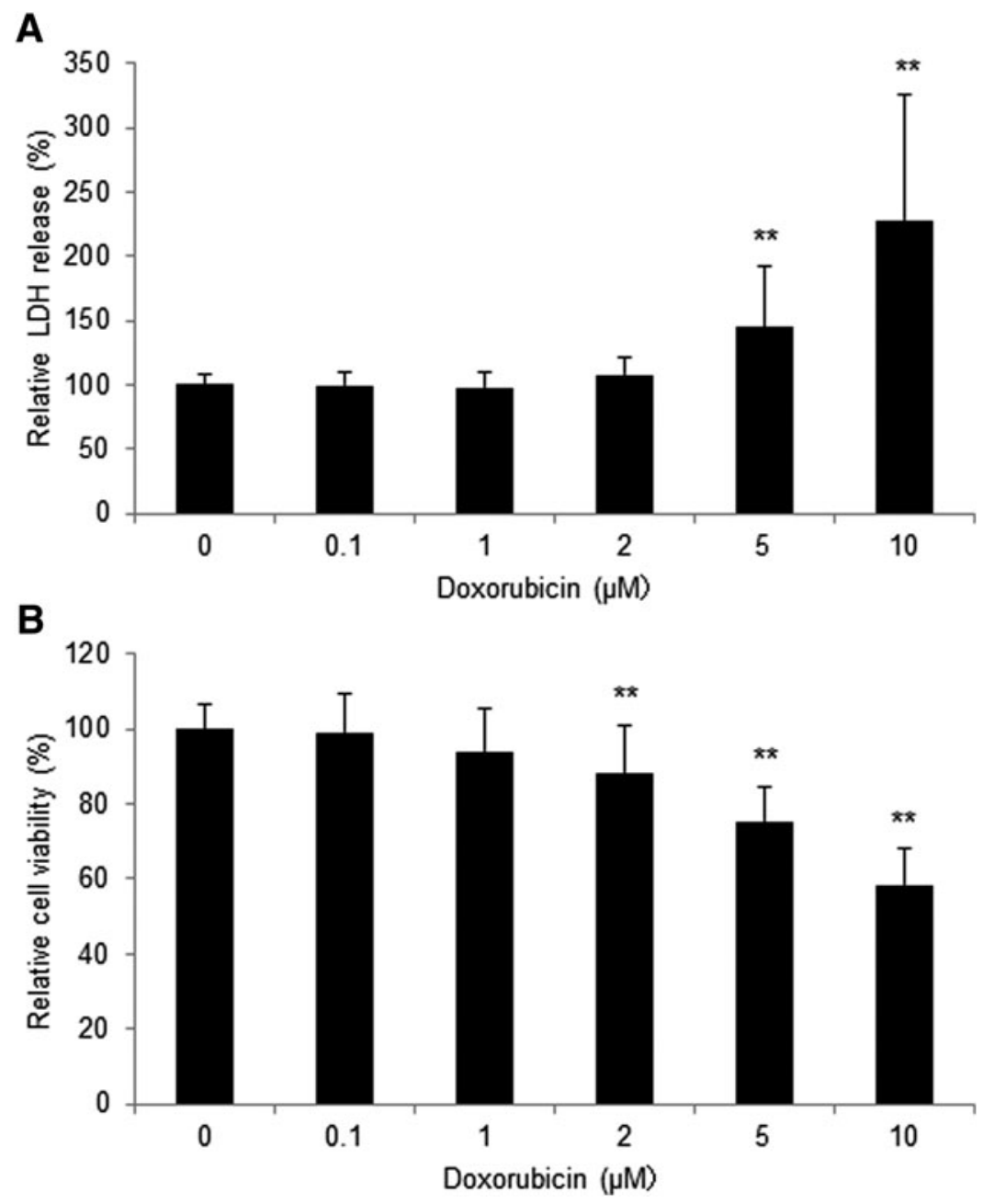

FIG. 3. Drug-induced cytotoxicity of 3D-hiPSC-CT. The normalized change in (A) the release of $\mathrm{LDH}$ and (B) cell viability with $0-10 \mu \mathrm{M}$ doxorubicin. $* * p<0.01$, compared with the vehicle control. LDH, lactate dehydrogenase.

3D-hiPSC-CT in a dose-dependent manner, and the concentrations that reduced cell viability significantly were $2 \mu \mathrm{M}$ $(88.4 \% \pm 13 \%, p<0.01$ vs. vehicle control), $5 \mu \mathrm{M}(75.3 \% \pm$ $9.0 \%, p<0.01$ vs. vehicle control), and $10 \mu \mathrm{M}(58.3 \% \pm 10 \%$, $p<0.01$ vs. vehicle control) (Fig. 3B).

\section{$\mathrm{Ca}^{2+}$ handling of $3 D$-hiPSC-CT in response to E-4031 and isoproterenol}

$\mathrm{Ca}^{2+}$ transient of 3D-hiPSC-CT in response to E-4031 or isoproterenol was assessed by FDSS/ $\mu$ CELL (Fig. 4A).

E-4031 at 30 and $100 \mathrm{nM}$ for $10 \mathrm{~min}$ induced a significant decrease in the $\mathrm{Ca}^{2+}$ peak ratio $(22.4 \pm 3.4 / \mathrm{min}, p<0.01$, $4.8 \pm 0.3 / \mathrm{min}, p<0.01$ vs. vehicle control [38.3 $\pm 2.6 / \mathrm{min}]$ ) and a significant increase in the $\mathrm{Ca}^{2+}$ peak interval $(2728.3 \pm 416.6 \mathrm{~ms}, p<0.01,12,563.1 \pm 805.9 \mathrm{~ms}, p<0.01$ vs. vehicle control $[1570.2 \pm 105.5 \mathrm{~ms}])$ in $3 \mathrm{D}$-hiPSC-CT (Fig. 4B-D). In addition, E-4031 at 10, 30, and $100 \mathrm{nM}$ induced a significant decrease in the downstroke slope $(11.2 \pm 2.1, p<0.01,34.1 \pm 0.7, p<0.01,1.0 \pm 0.5, p<0.01$ vs. vehicle control $[16.2 \pm 1.5])$ and a significant increase in the $90 \%$ peak width duration (PWD90) $(867.3 \pm 37.0 \mathrm{~ms}$, $p<0.01,1944.3 \pm 300.2 \mathrm{~ms}, p<0.01,11,866.6 \pm 942.0 \mathrm{~ms}$, $p<0.01$ vs. vehicle control $[741.7 \pm 13.5 \mathrm{~ms}]$ ) (Fig. 4E, F).

In contrast, isoproterenol at 10,100 , and $1000 \mathrm{nM}$ for $5 \mathrm{~min}$ induced a significant increase in the $\mathrm{Ca}^{2+}$ peak ratio (55.0 \pm 4.4 / $\min , p<0.01,54.5 \pm 1.9 / \mathrm{min}, p<0.01,51.6 \pm 4.6 / \mathrm{min}, p<0.01$ vs. vehicle control $[35.1 \pm 0.9 / \mathrm{min}])$ and in the upstroke slope $(47.6 \pm 6.2, p<0.05,46.7 \pm 4.4, p<0.05,66.1 \pm 10.4, p<0.01$ vs. vehicle control [38.6 \pm 3.4$]$ ), and a significant decrease in the $\mathrm{Ca}^{2+}$ peak interval $(1097.0 \pm 85.1 \mathrm{~ms}, p<0.01,1102.8 \pm 40.1 \mathrm{~ms}$, $p<0.01, \quad 1168.6 \pm 106.5 \mathrm{~ms}, \quad p<0.01$ vs. vehicle control $[1710.9 \pm 42.4 \mathrm{~ms}])$ and in the PWD90 $(671.9 \pm 28.7 \mathrm{~ms}$, $p<0.01,647.0 \pm 21.8 \mathrm{~ms}, p<0.01,660.4 \pm 16.4 \mathrm{~ms}, p<0.01 \mathrm{vs}$. vehicle control $[805.3 \pm 14.6 \mathrm{~ms}]$ ) (Fig. 5A-E).

\section{Contractile property of the $3 D-i P S C-C T$ in response to $E-4031$ and isoproterenol}

Change in contractile property of the 3D-iPSC-CT in response to E-4031 and isoproterenol was assessed by the Cell Motion Imaging System (Fig. 6A).

E-4031 at 30 and $100 \mathrm{nM}$ for $10 \mathrm{~min}$ induced a significant decrease in the beating rate $(32.7 \pm 1.2 / \mathrm{min}, p<0.01$, $29.6 \pm 1.7 / \mathrm{min}, p<0.01$ vs. vehicle control $[37.4 \pm 1.5 / \mathrm{min}]$ ) and a significant increase in the contraction-relaxation duration (CRD) $(0.81 \pm 0.03 \mathrm{~s}, p<0.01,0.98 \pm 0.04 \mathrm{~s}, p<0.01$ vs. vehicle control $[0.71 \pm 0.01 \mathrm{~s}])$. In addition, the contraction-relaxation velocities were significantly decreased at 10,30 , and $100 \mathrm{nM}$ of E-4031 for $10 \mathrm{~min}$ (contraction velocity; $9.5 \pm 1.3 \mu \mathrm{m} / \mathrm{s}, p<0.01,9.8 \pm 2.0 \mu \mathrm{m} / \mathrm{s}, p<0.05,9.8 \pm$ $1.5 \mu \mathrm{m} / \mathrm{s}, \quad p<0.05$ vs. vehicle control $[14.7 \pm 2.0 \mu \mathrm{m} / \mathrm{s}]$, 
A

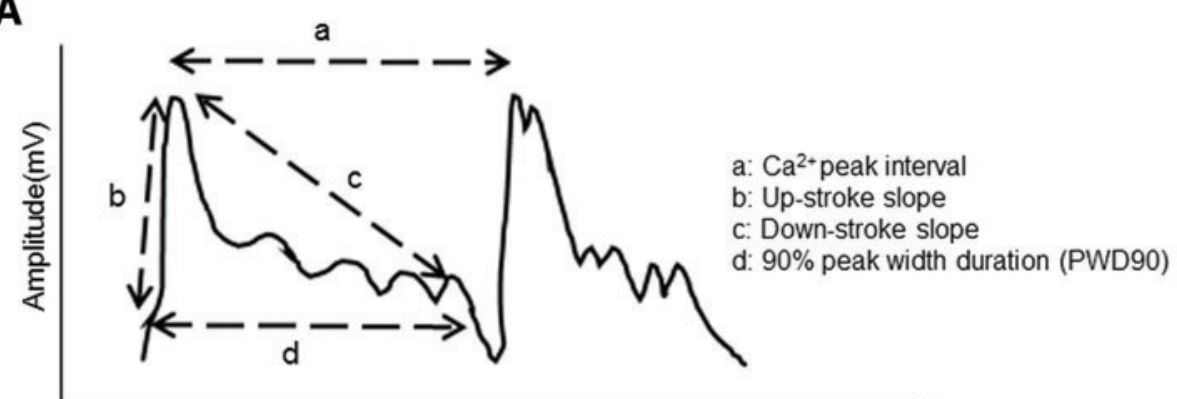

Time (ms)

B

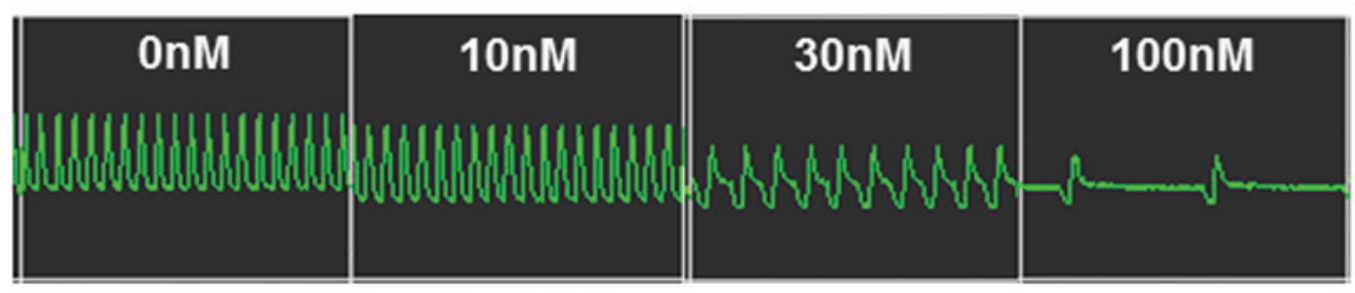

C

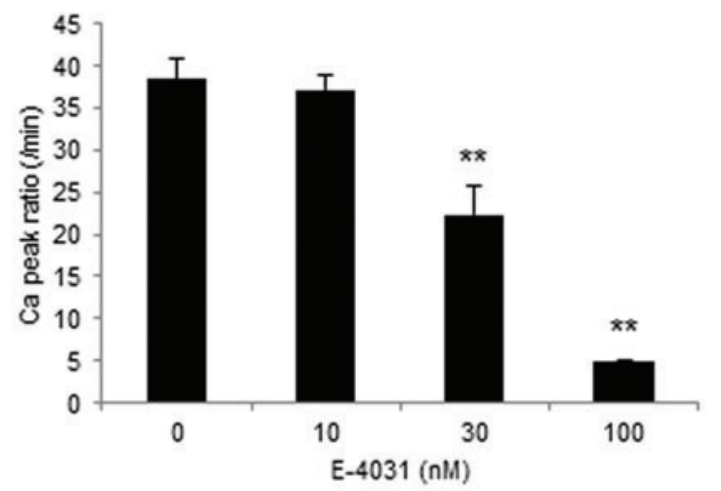

D

$\mathbf{E}$
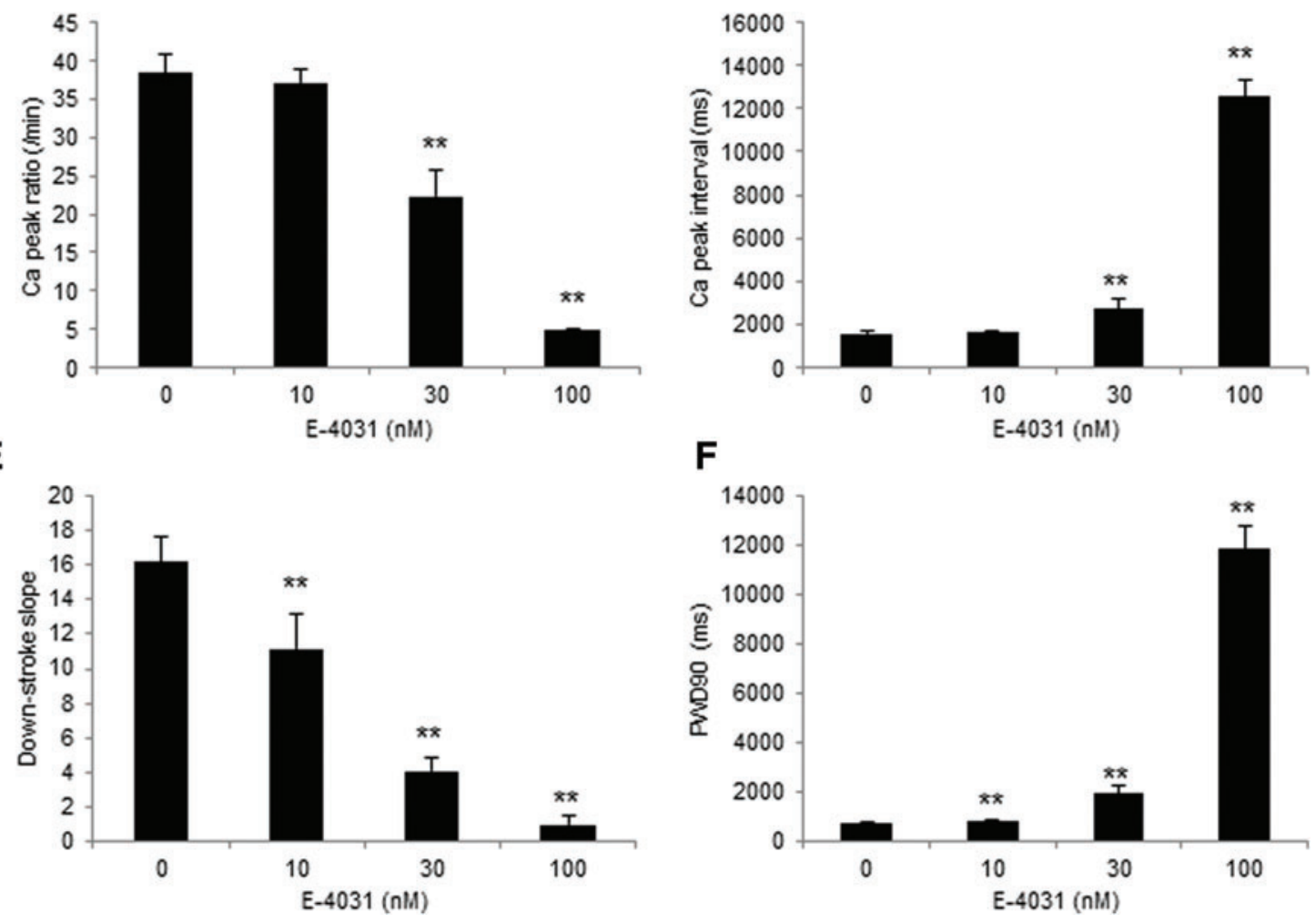

FIG. 4. $\mathrm{Ca}^{2+}$ Handling of $3 \mathrm{D}-\mathrm{hiPSC}-\mathrm{CT}$ by adding E-4031 for $10 \mathrm{~min}$. (A) Schematic diagram of the $\mathrm{Ca}^{2+}$ transient analysis. a: peak $\mathrm{Ca}^{2+}$ interval, b: upstroke slope, c: downstroke slope, d: 90\% peak width duration (PWD90). (B) Representative $\mathrm{Ca}^{2+}$ transient waveform after the addition of E-4031. Peak $\mathrm{Ca}^{2+}$ ratio (C), $\mathrm{Ca}^{2+}$ peak interval (D), downstroke slope (E), and PWD90 (F) of 3D-hiPSC-CT. ${ }^{* *} p<0.01$, compared with the vehicle control. Color images available online at www.liebertpub.com/tec 
A

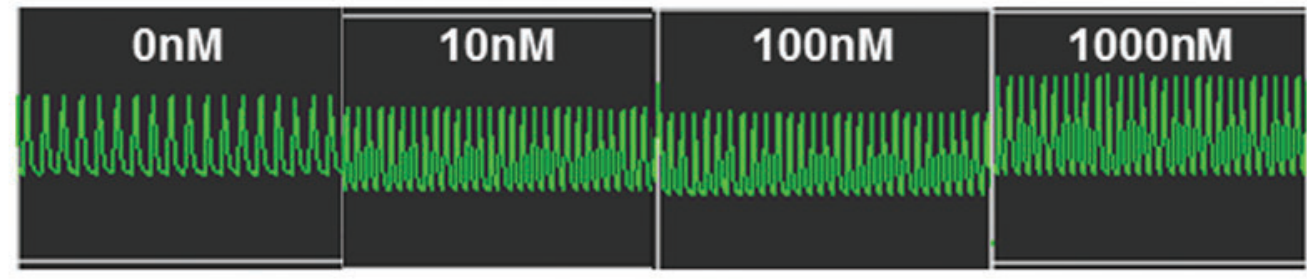

B

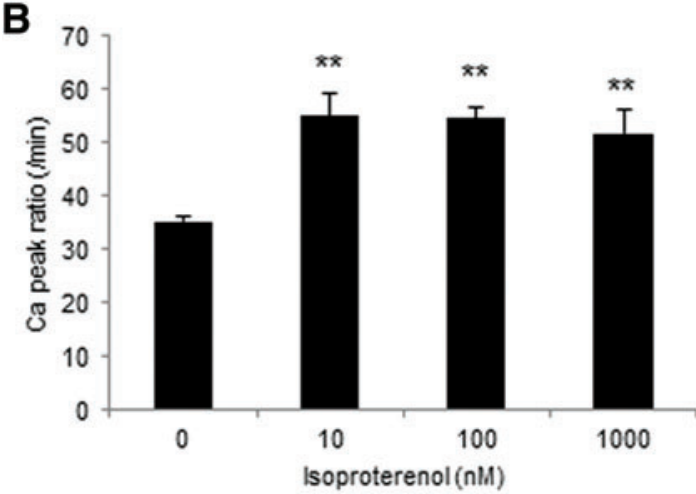

D

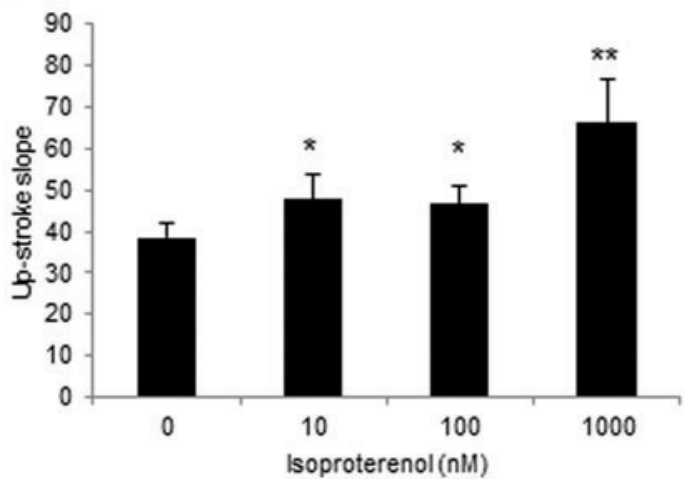

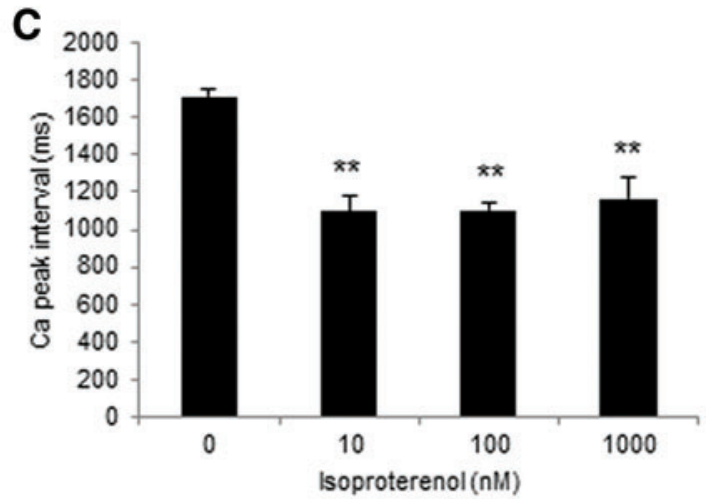

E

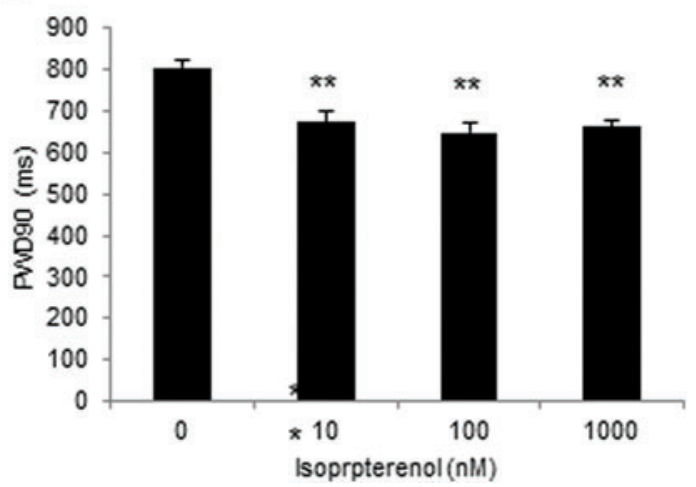

FIG. 5. $\mathrm{Ca}^{2+}$ Handling of 3D-hiPSC-CT by adding isoproterenol for 5 min. (A) Representative $\mathrm{Ca}^{2+}$ transient waveform after the addition of isoproterenol. Peak $\mathrm{Ca}^{2+}$ ratio $(\mathbf{B}), \mathrm{Ca}^{2+}$ peak interval $(\mathbf{C})$, upstroke slope $(\mathbf{D})$, and PWD90 (E) of 3D-hiPSCCT. ${ }^{*} p<0.05,{ }^{*} p<0.01$, compared with the vehicle control. Color images available online at www.liebertpub.com/tec

relaxation velocity; $6.5 \pm 1.3 \mu \mathrm{m} / \mathrm{s}, p<0.05,5.8 \pm 1.4 \mu \mathrm{m} / \mathrm{s}$, $p<0.01,6.4 \pm 0.6 \mu \mathrm{m} / \mathrm{s}, p<0.01$ vs. vehicle control [9.8 \pm $1.1 \mu \mathrm{m} / \mathrm{s}]$ ) (Fig. 6B-E).

In contrast, isoproterenol at 10,100 , and $1000 \mathrm{nM}$ for 10 min induced a significant increase in the beating rate $(49.7 \pm 1.5 / \mathrm{min}, p<0.01,58.3 \pm 1.3 / \mathrm{min}, p<0.01,59.2 \pm$ $1.37 / \mathrm{min}, p<0.01$ vs. vehicle control $[35.0 \pm 3.2 / \mathrm{min}])$ and a significant decrease in CRD $(0.54 \pm 0.008 \mathrm{~s}, p<0.01,0.52 \pm$ $0.01 \mathrm{~s}, p<0.01,0.52 \pm 0.02 \mathrm{~s}, p<0.01$ vs. vehicle control $[0.61 \pm 0.01 \mathrm{~s}])$. In addition, contraction-relaxation velocities were significantly increased at 10 and $100 \mathrm{nM}$ (contraction velocity; $28.6 \pm 1.0 \mu \mathrm{m} / \mathrm{s}, p<0.01,25.4 \pm 1.8 \mu \mathrm{m} / \mathrm{s}$, $p<0.01$ vs. vehicle control $[18.2 \pm 2.4 \mu \mathrm{m} / \mathrm{s}]$, relaxation velocity; $15.7 \pm 2.4 \mu \mathrm{m} / \mathrm{s}, p<0.05,16.5 \pm 2.8 \mu \mathrm{m} / \mathrm{s}, p<0.05$ vs. vehicle control $[11.5 \pm 1.6 \mu \mathrm{m} / \mathrm{s}])$ (Fig. $7 \mathrm{~A}-\mathrm{D})$.

\section{Discussion}

In this study, we found that the 3D-hiPSC-CT generated from single hiPSC-derived cardiomyocytes coated with fi- bronectin and gelatin displayed multilayered cells exhibiting cardiac-specific structural proteins and matrix proteins in the extracellular space. The 3D-hiPSC-CT exhibited a cytotoxic response against doxorubicin. Furthermore, 3D-hiPSC-CT exhibited a decrease in the $\mathrm{Ca}^{2+}$ peak ratio and the downstroke slope and an increase in the $\mathrm{Ca}^{2+}$ peak interval and PWD90 in response to E-4031, and an increase in the $\mathrm{Ca}^{2+}$ peak ratio and the upstroke slope and a decrease in the $\mathrm{Ca}^{2+}$ peak interval and PWD90 in response to isoproterenol. The 3D-hiPSC-CT also exhibited a decrease in the beating rate and contraction-relaxation velocities in response to E-4031 and an increase in the beating rate and contraction-relaxation velocities in response to isoproterenol. Given these findings, 3D-hiPSC-CT appear to have potential utility in the evaluation of drug-induced toxicity and pharmacological action in vitro.

The 3D-hiPSC-CT displayed completely synchronized mechanical and electrophysiological properties. Links between the layered cardiac myocytes by the connexin 43 gap junction, which was clearly shown immunohistologically, 
FIG. 6. Contractile property of 3D-hiPSC-CT in response to E-4031 for $10 \mathrm{~min}$. (A) Schematic diagram of the contractile properties analysis. a: contraction velocity, b: relaxation velocity, c: CRD. Beating rate (B), contraction velocity (C), relaxation velocity (D), and CRD (E) of 3D-hiPSC-CT. $* p<0.05, * * p<0.01$, compared with the vehicle control. CRD, contractionrelaxation duration.

FIG. 7. Contractile property of 3D-hiPSC-CT in response to isoproterenol for 10 min. Beating rate

(A), contraction velocity (B), relaxation velocity (C), and CRD (D) of 3DhiPSC-CT. $* p<0.05$, $* * p<0.01$, compared with the vehicle control.



Time(ms)

\section{B}

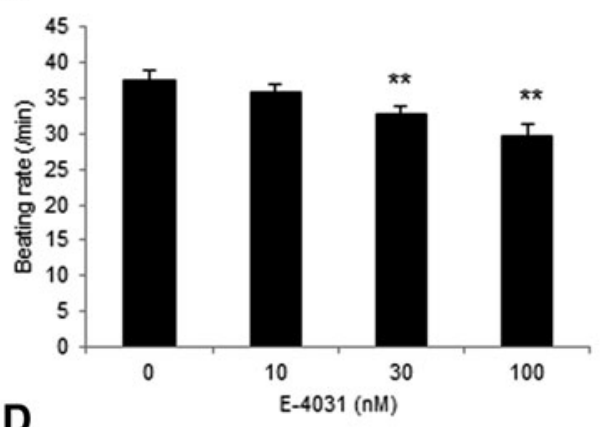

D

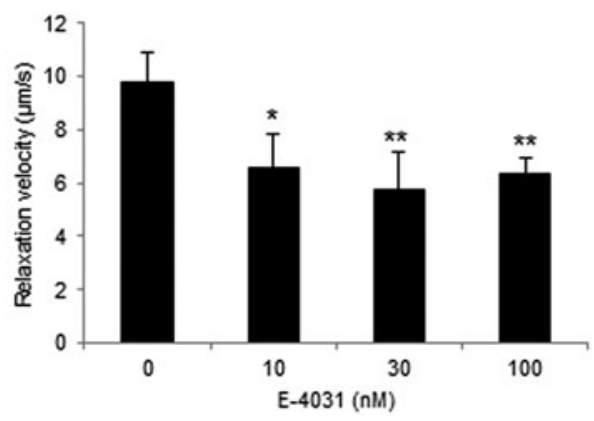

A

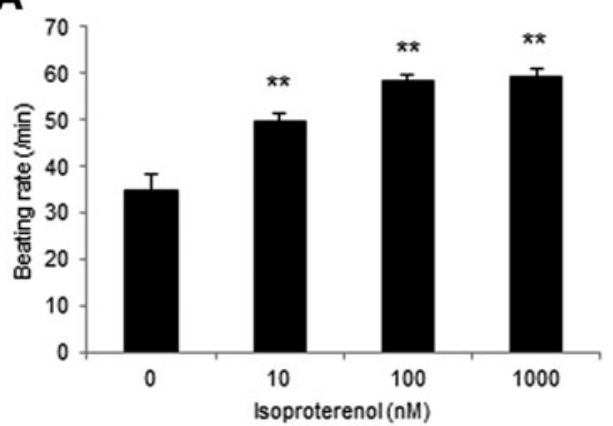

C

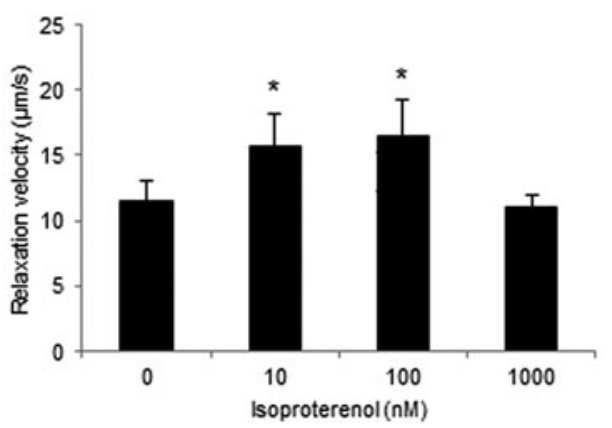

C



E

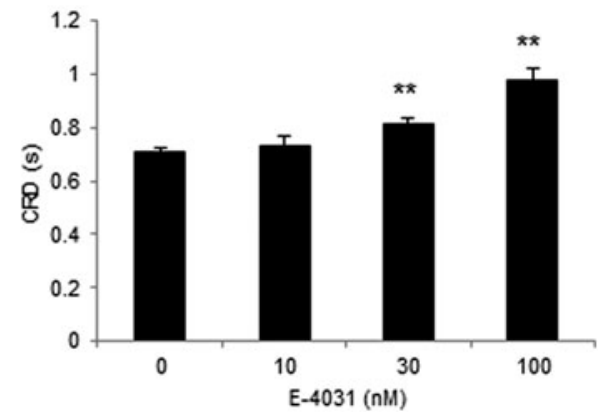

B

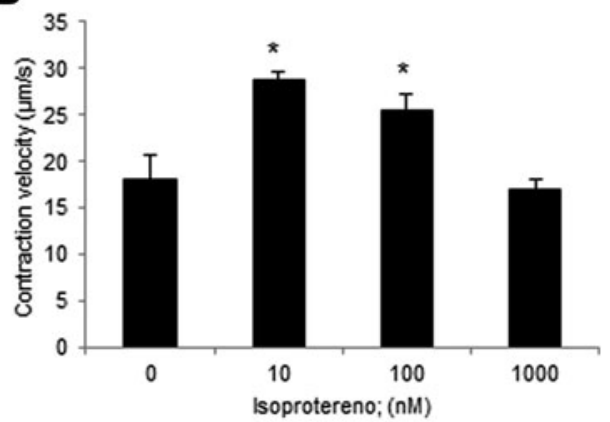

D




would be a major positive contributor to enhanced properties as cardiac tissue for 3D-hiPSC-CT. Some claim that layered artificial cardiac tissue induces ischemic changes in the centered cardiac myocytes, producing mechanical and electrophysiological heterogeneity without a microvascular network. However, the 3D-hiPSC-CT with a $50 \mu \mathrm{m}$ thickness did not show heterogeneity in the electrical propagation, suggesting that addition of a microvascular network would not be necessarily required to preserve the functionality of $\leq 50-\mu$ m-thick 3D-hiPSC-CT.

The minimum effective concentration of doxorubicin for 24-h cytotoxicity of 3D-hiPSC-CT was $5.0 \mu \mathrm{M}$ in the LDH assay and $2.0 \mu \mathrm{M}$ in the CCK8 assay in this study. Since the reported minimum effective concentration of doxorubicin in single or monolayer hiPSC-derived cardiomyocytes is not substantially different from that obtained in this study, the 3D-hiPSC-CT may carry a comparative tolerance against doxorubicin to single cardiomyocytes or the monolayered cardiomyocytes. ${ }^{33-36}$ Since the cytotoxic effects of doxorubicin directly target DNA degradation and early apoptosis, these results indicate the homogeneous delivery of doxorubicin into the cardiomyocytes of entire 3D-hiPSC-CT, suggesting the utility of 3D-hiPSC-CT for drug screening tests.

Our study showed that the minimum effective concentration of E-4031 on the $\mathrm{Ca}^{2+}$ transient and contractionrelaxation performance of 3D-hiPSC-CT was $10 \mathrm{nM}$ for $10 \mathrm{~min}$, findings comparable to the reported concentration of E-4031 $(10 \mathrm{nM})$ in the examination using single dissociated cells. ${ }^{37}$ Some articles have reported that the minimum effective concentration of E-4031 ranges from 3 to $100 \mathrm{nM}$ and these reported data suggest that the effects of E-4031 on the $\mathrm{Ca}^{2+}$ transient and contraction-relaxation performance in 3D-hiPSC-CT might be comparative to that of standard assays, such as hERG, patch clamp, and MEA. ${ }^{38-44}$ Our results showed greater drug sensitivity than animal studies, indicating an adequate, at least not inferior, effect of E-4031 on the 3D-hiPSC-CT compared to the standard methods. ${ }^{45}$

In addition, the $\mathrm{Ca} 2+$ transient levels in 3D-hiPSC-CT changed with the administration of isoproterenol at $10 \mathrm{nM}$ for $5 \mathrm{~min}$. Furthermore, the contraction-relaxation performance of 3D-hiPSC-CT increased with the administration of isoproterenol at $10 \mathrm{nM}$ for $10 \mathrm{~min}$. The effective concentration of isoproterenol has been reported to range from 10 to $1000 \mathrm{nM}$. Our results therefore achieved equivalent or superior detecting potential for isoproterenol compared with the standard methods or adult human heart slices. ${ }^{46-48}$

Since most of articles monitored drug responses for 1060 min after adding E-4031 or isoproterenol, monitoring time in this study is enough. However, it is necessary to consider the monitoring time for evaluating chronic drug responses.

We should also evaluate the appropriateness of this screening system for cardiotoxicity. To validate this system, we should compare the in vitro evaluation using $3 \mathrm{D}$ cardiac tissue with an in vivo screening system using a small animal or Langendorff experiments, or compare ours with other in vitro screening systems.

Fibronectin-/gelatin-coated cells were used to generate the 3D-hiPSC-CT, which achieved a uniform artificial cardiac tissue, contributing to the standardization of the protocol of 3D-hiPSC-CT production, as reported by our laboratory for the production of skin, liver, or blood vessel models of 3D artificial tissue. ${ }^{49,50}$ Although 3D-hiPSC-CT with a $50-\mu \mathrm{m}$ thickness was used in this study, layered 3DhiPSC-CT with a developed vascular network might more accurately mimic the microstructure and functionality of human cardiac tissue. Our protocol makes it easy to construct thick tissues without artificial scaffolds by increasing the number of coated cells to be seeded. Moreover, the development of 3D printing techniques to fabricate 3D tissues automatically is now in progress. ${ }^{51}$ This protocol therefore has the potential to be scaled and applied to various experimental settings. This study may be limited by the use of a single cell line of iPSCs that were cardiomyogenically differentiated in a single protocol. hiPSC-CM included about $60 \%$ cardiomyocytes in this study. Although the differentiation method needs to be improved, our laboratory previously reported that engineered cardiac tissues containing 50-70\% cardiomyocytes exhibited stable structures. ${ }^{52}$ The optimum ratio of cardiomyocytes in the 3D models should be considered. Drugs act on cardiomyocytes directly or indirectly through surrounding cells. To more closely mimic the drug response in the in vivo environment, it might be useful to construct 3D-hiPSC-CT mixed with fibroblast or endothelial cells and verify their optimum ratio. Furthermore, 3D models generated using various numbers of cells with different ratios may be used to evaluate the effects of drugs not only on cardiotoxicity but also on angiogenesis or fibrosis.

In conclusion, the 3D-hiPSC-CT detected doxorubicinsensitive cytotoxicity and hERG channel blocker/isoproterenolsensitive electrical/mechanical activities in vitro, indicating its usefulness for drug-induced cardiotoxicity assays or in drug screening systems for drug discovery.

\section{Acknowledgments}

We acknowledge Tsuyoshi Ishikawa and Nobu Miyakawa for expert technical assistance. This work was supported by the SENTAN-JST Program, Research Project for Practical Application of Regenerative Medicine and Health Labour Sciences Research Grant.

\section{Disclosure Statement}

No competing financial interests exist.

\section{References}

1. Hughes, J.P., Rees, S., Kalindjian, S.B., and Philpott, K.L. Principles of early drug discovery. Br J Pharmacol 162, 1239, 2011.

2. Qureshi, Z.P., Seoane-Vazquez, E., Rodriguez-Monguio, R., Stevenson, K.B., and Szeinbach, S.L. Market withdrawal of new molecular entities approved in the United States from 1980 to 2009. Pharmacoepidemiol Drug Saf 20, 772, 2011.

3. Gwathmey, J.K., Tsaioun, K., and Hajjar, R.J. Cardionomics: a new integrative approach for screening cardiotoxicity of drug candidates. Expert Opin Drug Metab Toxicol 5, 647, 2009.

4. Roth, G.A., Dwyer-Lindgren, L., Bertozzi-Villa, A., et al. Trends and patterns of geographic variation in cardiovascular mortality among US counties, 1980-2014. JAMA 317, 1976, 2017. 
5. Stevens, J.L., and Baker, T.K. The future of drug safety testing: expanding the view and narrowing the focus. Drug Discov Today 14, 162, 2009.

6. Martin, R.L., McDermott, J.S., Salmen, H.J., Palmatier, J., Cox, B.F., and Gintant, G.A. The utility of hERG and repolarization assays in evaluating delayed cardiac repolarization: influence of multi-channel block. J Cardiovasc Pharmacol 43, 369, 2004.

7. Redfern, W.S., Carlsson, L., Davis, A.S., et al. Relationships between preclinical cardiac electrophysiology, clinical QT interval prolongation and torsade de pointes for a broad range of drugs: evidence for a provisional safety margin in drug development. Cardiovasc Res 58, 32, 2003.

8. Dumotier, B.M., Deurinck, M., Yang, Y., Traebert, M., and Suter, W. Relevance of in vitro SCREENIT results for drug-induced QT interval prolongation in vivo: a database review and analysis. Pharmacol Ther 119, 152, 2008.

9. Jonsson, M.K., Vos, M.A., Mirams, G.R., et al. Application of human stem cell-derived cardiomyocytes in safety pharmacology requires caution beyond hERG. J Mol Cell Cardiol 52, 998, 2012.

10. Mandenius, C.F., Steel, D., Noor, F., et al. Cardiotoxicity testing using pluripotent stem cell-derived human cardiomyocytes and state-of-the-art bioanalytics: a review. J Appl Toxicol 31, 191, 2011.

11. Guo, L., Abrams, R.M., Babiarz, J.E., et al. Estimating the risk of drug-induced proarrhythmia using human induced pluripotent stem cell-derived cardiomyocytes. Toxicol Sci 123, 281, 2011.

12. Lu, H.R., Mariën, R., Saels, A., and De Clerck, F. Species plays an important role in drug-induced prolongation of action potential duration and early afterdepolarizations in isolated Purkinje fibers. J Cardiovasc Electrophysiol 12, 93, 2001.

13. Olson, H., Betton, G., Robinson, D., et al. Concordance of the toxicity of pharmaceuticals in humans and in animals. Regul Toxicol Pharmacol 32, 56, 2000.

14. Lawrence, C.L., Pollard, C.E., Hammond, T.G., and Valentin, J.P. Nonclinical proarrhythmia models: predicting Torsades de Pointes. J Pharmacol Toxicol Methods 52, 46, 2005.

15. Guo, L., Coyle, L., Abrams, R.M., Kemper, R., Chiao, E.T., and Kolaja, K.L. Refining the human iPSC-cardiomyocyte arrhythmic risk assessment model. Toxicol Sci 136, 581, 2013.

16. Peters, M.F., Lamore, S.D., Guo, L., Scott, C.W., and Kolaja, K.L. Human stem cell-derived cardiomyocytes in cellular impedance assays: bringing cardiotoxicity screening to the front line. Cardiovasc Toxicol 15, 127, 2015.

17. Sinnecker, D., Laugwitz, K.L., and Moretti, A. Induced pluripotent stem cell-derived cardiomyocytes for drug development and toxicity testing. Pharmacol Ther 143, 246, 2014.

18. Braam, S.R., Passier, R., and Mummery, C.L. Cardiomyocytes from human pluripotent stem cells in regenerative medicine and drug discovery. Trends Pharmacol Sci 30, 536, 2009.

19. Mordwinkin, N.M., Burridge, P.W., and Wu, J.C. A review of human pluripotent stem cell-derived cardiomyocytes for high-throughput drug discovery, cardiotoxicity screening, and publication standards. J Cardiovasc Transl Res 6, 22, 2013.

20. Moretti, A., Bellin, M., Welling, A., et al. Patient-specific induced pluripotent stem-cell models for long-QT syndrome. N Engl J Med 363, 1397, 2010.

21. Matsa, E., Rajamohan, D., Dick, E., et al. Drug evaluation in cardiomyocytes derived from human induced pluripotent stem cells carrying a long QT syndrome type 2 mutation. Eur Heart J 32, 952, 2011.
22. Liang, P., Lan, F., Lee, A.S., et al. Drug screening using a library of human induced pluripotent stem cell-derived cardiomyocytes reveals disease-specific patterns of cardiotoxicity. Circulation 127, 1677, 2013.

23. Yamashita, A., Morioka, M., Kishi, H., et al. Statin treatment rescues FGFR3 skeletal dysplasia phenotypes. Nature 513, 507, 2014.

24. Otsuji, T.G., Minami, I., Kurose, Y., Yamauchi, K., Tada, M., and Nakatsuji, N. Progressive maturation in contracting cardiomyocytes derived from human embryonic stem cells: qualitative effects on electrophysiological responses to drugs. Stem Cell Res 4, 201, 2010.

25. Nalos, L., Varkevisser, R., Jonsson, M.K., et al. Comparison of the $\mathrm{IKr}$ blockers moxifloxacin, dofetilide and E-4031 in five screening models of pro-arrhythmia reveals lack of specificity of isolated cardiomyocytes. Br J Pharmacol 165, 467, 2012.

26. Huebsch, N., Loskill, P., Deveshwar, N., et al. Miniaturized iPS-cell-derived cardiac muscles for physiologically relevant drug response analyses. Sci Rep 6, 24726, 2016.

27. Zhen, M., Sangmo, K., Micaela, A., et al. Three dimension filamentous human cardiac tissue model. Biomaterials 35, 1367, 2014.

28. Lu, H.F., Leong, M.F., Lim, T.C.,et al. Engineering a functional three-dimensional human cardiac tissue model for drug toxicity screening. Biofabrication 9, 025011, 2017.

29. Zhao, Q., Wang, X., Wang, S., Song, Z., Wang, J., and Ma, J. Cardiotoxicity evaluation using human embryonic stem cells and induced pluripotent stem cell-derived cardiomyocytes. Stem Cell Res Ther 8, 54, 2017.

30. Oberwallner, B., Brodarac, A., Choi, Y.H., et al. Preparation of cardiac extracellular matrix scaffolds by decellularization of human myocardium. J Biomed Mater Res A 102, 3263, 2014.

31. Nishiguchi, A., Matsusaki, M., Miyagawa, S., Sawa, Y., and Akashi, M. Dynamic nano-interfaces enable harvesting of functional 3D-engineered tissues. Adv Healthc Mater 4, 1164, 2015.

32. Nishiguchi, A., Yoshida, H., Matsusaki, M., and Akashi, M. Rapid construction of three-dimensional multilayered tissues with endothelial tube networks by the cellaccumulation technique. Adv Mater 23, 3506, 2011.

33. Pereira, G.C., Silva, A.M., Diogo, C.V., Carvalho, F.S., Monteiro, P., and Oliveira, P.J. Drug-induced cardiac mitochondrial toxicity and protection: from doxorubicin to carvedilol. Curr Pharm Des 17, 2113, 2011.

34. Sirenko, O., Cromwell, E.F., Crittenden, C., Wignall, J.A., Wright, F.A., and Rusyn, I. Assessment of beating parameters in human induced pluripotent stem cells enables quantitative in vitro screening for cardiotoxicity. Toxicol Appl Pharmacol 273, 500, 2013.

35. Holmgren, G., Synnergren, J., Bogestål, Y., et al. Identification of novel biomarkers for doxorubicin-induced toxicity in human cardiomyocytes derived from pluripotent stem cells. Toxicology 328, 102, 2015.

36. Mioulane, M., Foldes, G., Ali, N.N., Schneider, M.D., and Harding, S.E. Development of high content imaging methods for cell death detection in human pluripotent stem cell-derived cardiomyocytes. J Cardiovasc Transl Res 5, 593, 2012.

37. Matsuzawa, A., Matsusaki, M., and Akashi, M. Construction of three-dimensional liver tissue models by cell accumulation technique and maintaining their metabolic functions for 
long-term culture without medium change. J Biomed Mater Res A 103, 1554, 2015.

38. Ma, J., Guo, L., Fiene, S.J., et al. High purity human-induced pluripotent stem cell-derived cardiomyocytes: electrophysiological properties of action potentials and ionic currents. Am J Physiol Heart Circ Physiol 301, H2006, 2011.

39. Tanaka, T., Tohyama, S., Murata, M., et al. In vitro pharmacologic testing using human induced pluripotent stem cell-derived cardiomyocytes. Biochem Biophys Res Commun 385, 497, 2009.

40. Honda, M., Kiyokawa, J., Tabo, M., and Inoue, T. Electrophysiological characterization of cardiomyocytes derived from human induced pluripotent stem cells. J Pharmacol Sci 117, 149, 2011.

41. Zwi, L., Caspi, O., Arbel, G., et al. Cardiomyocyte differentiation of human induced pluripotent stem cells. Circulation 120, 1513, 2009.

42. Harris, K., Aylott, M., Cui, Y., Louttit, J.B., McMahon, N.C., and Sridhar, A. Comparison of electrophysiological data from human-induced pluripotent stem cell-derived cardiomyocytes to functional preclinical safety assays. Toxicol Sci 134, 412, 2013.

43. Mathur, A., Loskill, P., Shao, K., et al. Human iPSC-based cardiac microphysiological system for drug screening applications. Sci Rep 5, 8883, 2015.

44. Hayakawa, T., Kunihiro, T., Ando, T., et al. Image-based evaluation of contraction-relaxation kinetics of humaninduced pluripotent stem cell-derived cardiomyocytes: correlation and complementarity with extracellular electrophysiology. J Mol Cell Cardiol 77, 178, 2014.

45. Ando, H., Yoshinaga, T., Yamamoto, W., et al. A new paradigm for drug-induced torsadogenic risk assessment using human iPS cell-derived cardiomyocytes. J Pharmacol Toxicol Methods 84, 111, 2017.

46. Navarrete, E.G., Liang, P., Lan, F., et al. Screening druginduced arrhythmia using human induced pluripotent stem cell-derived cardiomyocytes and low-impedance microelectrode arrays. Circulation 128, S3, 2013.

47. Watanabe, H., Honda, Y., Deguchi, J., Yamada, T., and Bando, K. Usefulness of cardiotoxicity assessment using calcium transient in human induced pluripotent stem cellderived cardiomyocytes. J Toxicol Sci 42, 519, 2017.

48. Nozaki, Y., Honda, Y., Watanabe, H., et al. CSAHi study-2: validation of multi-electrode array systems (MEA60/2100) for prediction of drug-induced proarrhythmia using human iPS cell-derived cardiomyocytes: assessment of reference compounds and comparison with non-clinical studies and clinical information. Regul Toxicol Pharmacol 88, 238, 2017.

49. Matsusaki, M., Fujimoto, K., Shirakata, Y., Hirakawa, S., Hashimoto, K., and Akashi, M. Development of fullthickness human skin equivalents with blood and lymphlike capillary networks by cell coating technology. J Biomed Mater Res A 103, 3386, 2015.

50. Matsusaki, M., Kadowaki, K., Adachi, E., et al. Morphological and histological evaluations of 3D-layered blood vessel constructs prepared by hierarchical cell manipulation. J Biomater Sci Polym Ed 23, 63, 2012.

51. Tsukamoto, Y., Akagi, T., Shima, F., and Akashi, M. Fabrication of orientation-controlled $3 \mathrm{D}$ tissues using a layer-bylayer technique and $3 \mathrm{D}$ printed a thermoresponsive gel frame. Tissue Eng Part C Methods 6, 357, 2017.

52. Iseoka, H., Miyagawa, S., Fukushima, S., et al. Pivotal role of non-cardiomyocytes in electromechanical and therapeutic potential of induced pluripotent stem cell-derived engineered cardiac tissue. Tissue Eng Part A [Epub ahead of print]; DOI: 10.1089/ten.TEA.2016.0535.

Address correspondence to: Yoshiki Sawa, MD, PhD Department of Cardiovascular Surgery Osaka University Graduate School of Medicine 2-2 Yamadaoka, Suita Osaka 565-0871 Japan

E-mail: sawa-p@surg1.med.osaka-u.ac.jp

Received: May 9, 2017

Accepted: September 21, 2017

Online Publication Date: November 7, 2017 